\title{
S,C-Sulfonium Ylides from Thiophenes: Potential Carbene Precursors
}

Stacey A. Stoffregen, Melanie Heying, and William S. Jenks*

Department of Chemistry, Iowa State University, Ames, Iowa 50011-3111

Supporting Information 


\section{Experimental details}

General. Cyclohexene was refluxed over sodium metal under an argon atmosphere and distilled immediately before use. Benzene and methylene chloride were refluxed over calcium hydride under an argon atmosphere and distilled immediately before use. Thiophene was distilled under vacuum using a short path distillation apparatus prior to its use.

Dibenzothiophene was distilled under vacuum using a Kügelrohr apparatus at $175^{\circ} \mathrm{C}$ prior to its use.

Materials. Dimethyl diazomalonate, ${ }^{1} p$-toluenesulfonyl azide, ${ }^{2}$ methyl phenyl sulfonium bismethoxycarbonylmethylide (1), ${ }^{3}$ thiophenium bismethoxycarbonyl-methylide (2), ${ }^{4}$ benzothiophenium bismethoxycarbonylmethylide (3), ${ }^{5}$ trimethylphosphite copper (I) chloride, ${ }^{5}$ 7,7-dimethoxycarbonylbicyclo[4.1.0]heptane (5), ${ }^{6}$ dimethyl (3-cyclohexenyl)malonate (6), ${ }^{6,7}$ tetramethoxycarbonylethylene (7), ${ }^{7}$ dimethyl dimethoxymalonate (8), ${ }^{8}$ and dimethyl 2 thienylmalonate $(\mathbf{1 0})^{9}$ were prepared by methods reported in the literature.

Dibenzothiophenium bismethoxycarbonylmethylide (4). To a $100 \mathrm{~mL}$ round bottomed flask, dibenzothiophene ( $0.93 \mathrm{~g}, 5.1 \mathrm{mmol})$, dimethyl diazomalonate $(0.12 \mathrm{~mL}, 1.0 \mathrm{mmol})$, rhodium acetate dihydrate $(2 \mathrm{mg})$, and 1,2-dichloroethane $(4 \mathrm{~mL})$ were added under an argon atmosphere. The mixture was stirred for $15 \mathrm{hrs,}$ at which time the mixture was a milky green color. The solvent was then removed under vacuum and hexane $(20 \mathrm{~mL})$ was added. The crude product was collected by vacuum filtration and subsequently purified by recrystallization from methanol. The title compound was a white solid. Yield: $79 \%$ ( $0.25 \mathrm{~g}) \mathrm{FW}=314.36 \mathrm{~g} / \mathrm{mol}$.

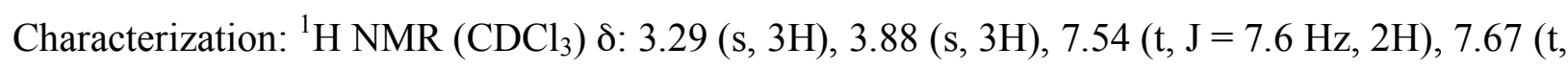

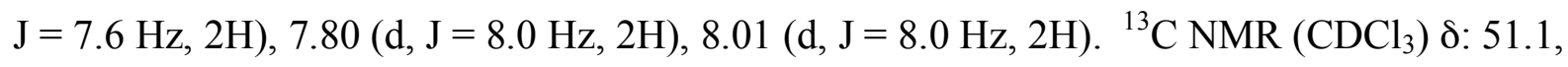
51.5, 57.5, 122.5, 125.0, 129.7, 131.4, 135.6, 137.4, 164.5, 167.8. EI-MS: Calc. 314 g/mol. 
Found $314(\mathrm{M}), 283\left(\mathrm{M}-\mathrm{OCH}_{3}\right), 255\left(\mathrm{M}-\mathrm{CO}_{2} \mathrm{CH}_{3}\right), 184\left(\mathrm{M}_{-} \mathrm{C}_{5} \mathrm{O}_{4} \mathrm{H}_{6}\right)$. IR $\left(\mathrm{cm}^{-1}\right)$ : 3054(sh), 2986(sh), 2305(sh), 1685(sh), 1649(sh).

Figure S1. ${ }^{1}$ H NMR dibenzothiophenium biscarbomethoxymethylide.

Solvent: deuterated chloroform.

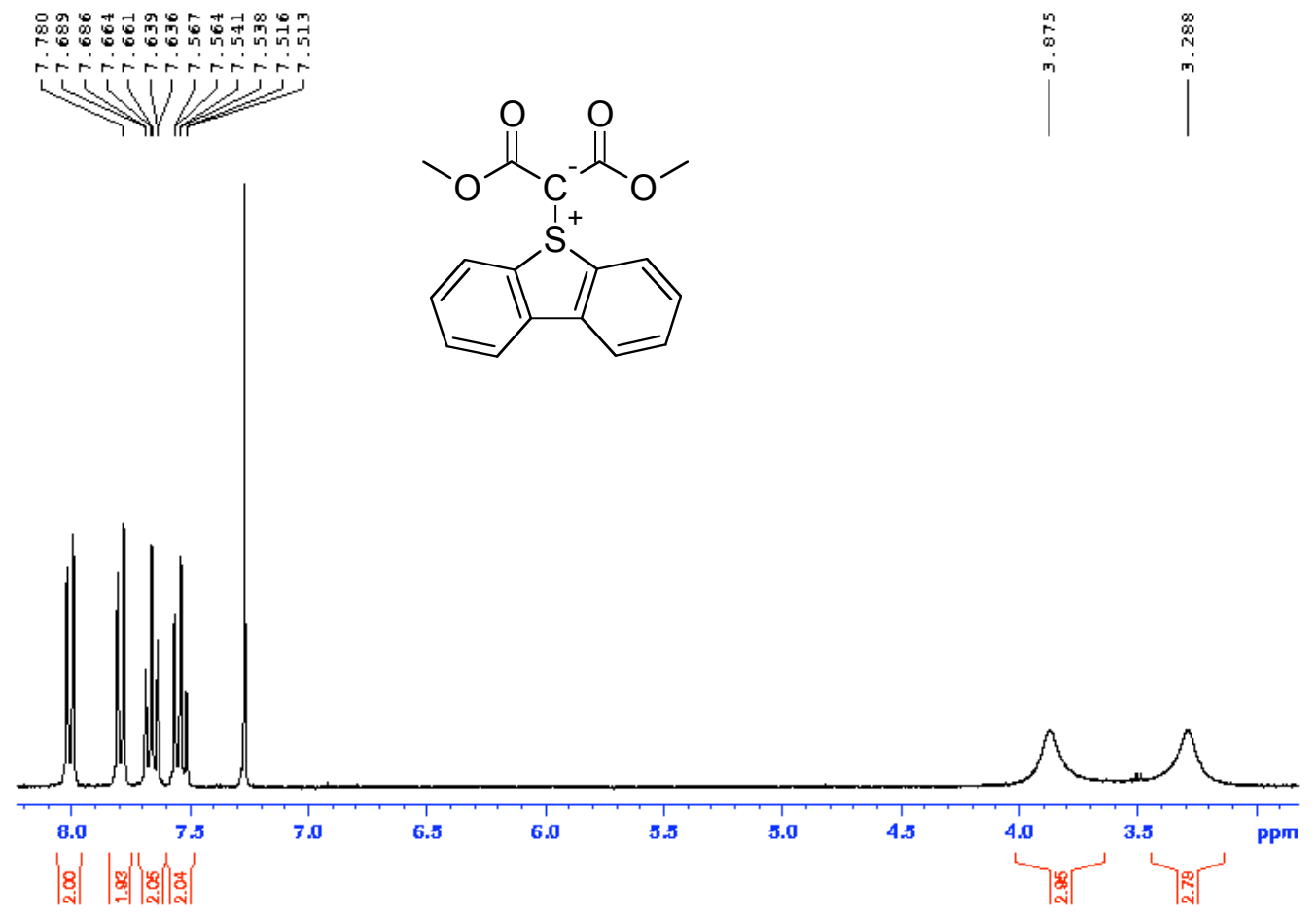


Figure S2. ${ }^{13} \mathrm{C}$ NMR dibenzothiophenium biscarbomethoxymethylide.

Solvent: deuterated chloroform.

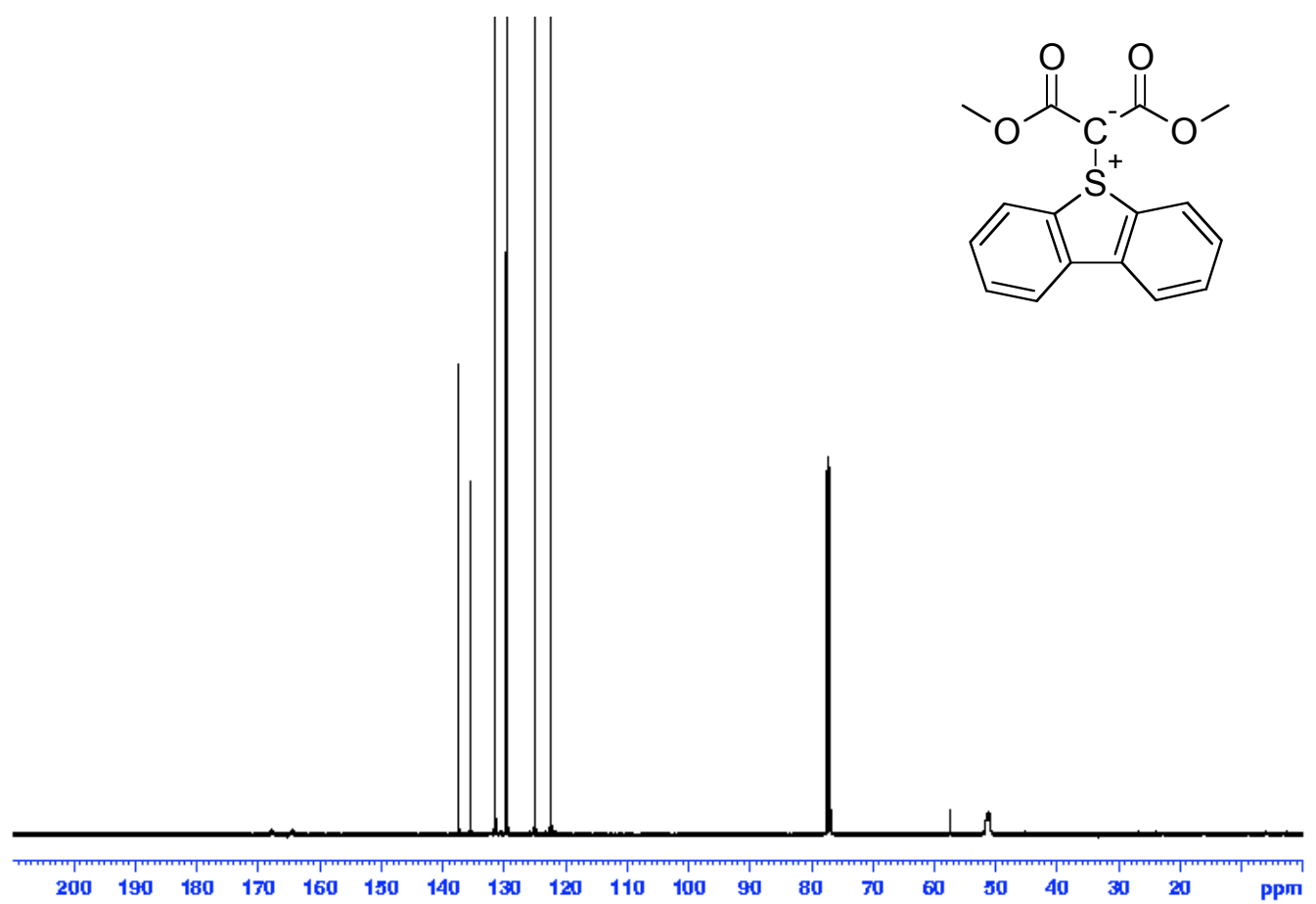


Figure S3. ${ }^{13} \mathrm{C}$ NMR-dibenzothiophenium biscarbomethoxymethylide (expanded).

Solvent: deuterated chloroform.
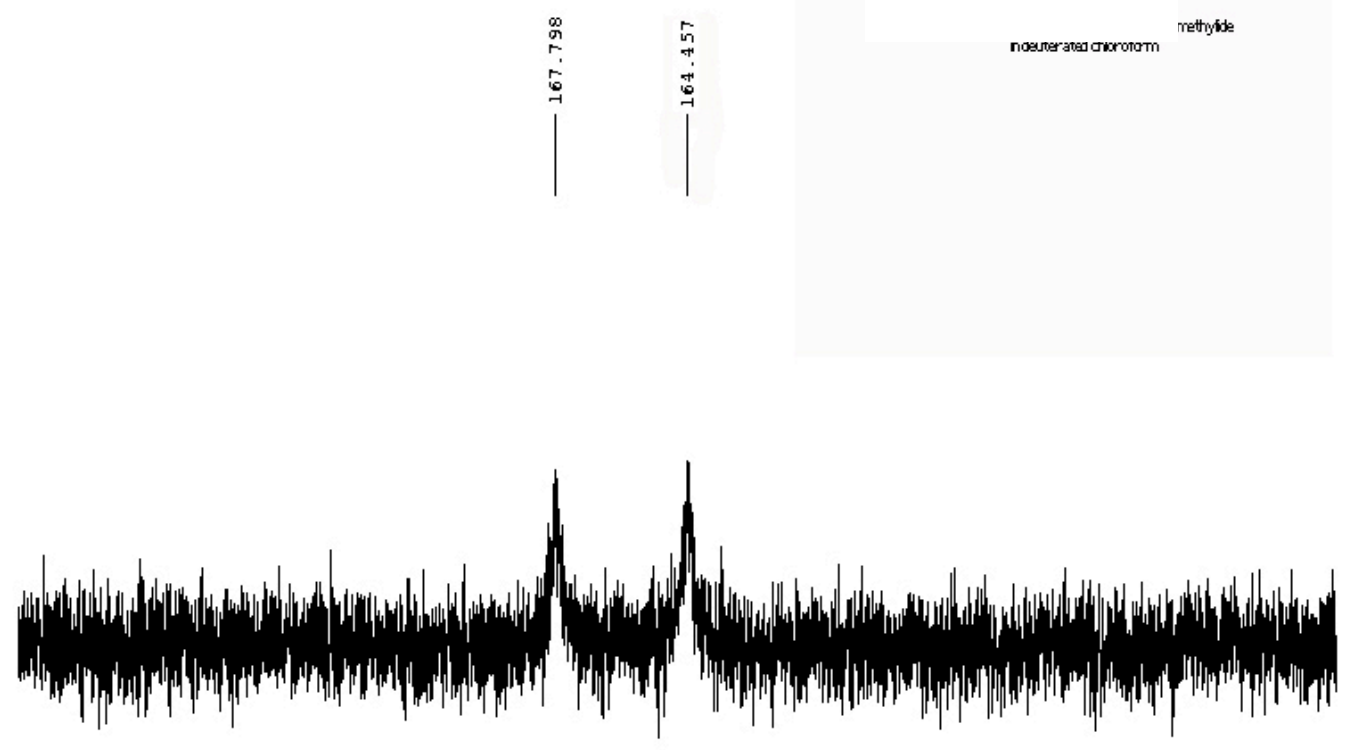

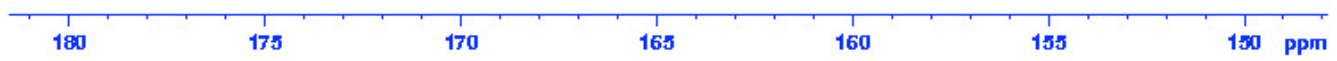


Figure S4. ${ }^{13} \mathrm{C}$ NMR-dibenzothiophenium biscarbomethoxymethylide (expanded).

Solvent: deuterated chloroform.
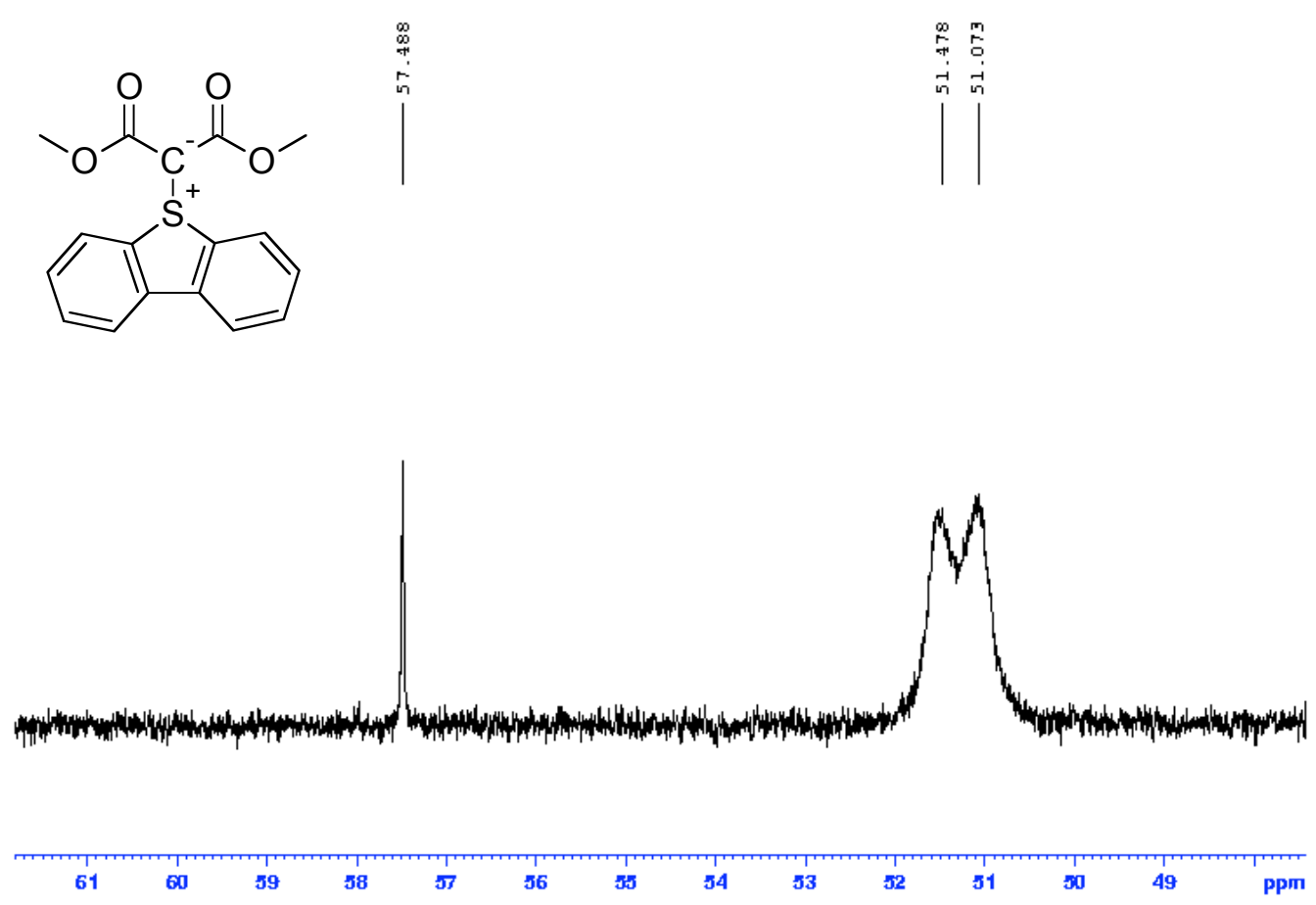

Figure S5. IR dibenzothiophenium biscarbomethoxymethylide.

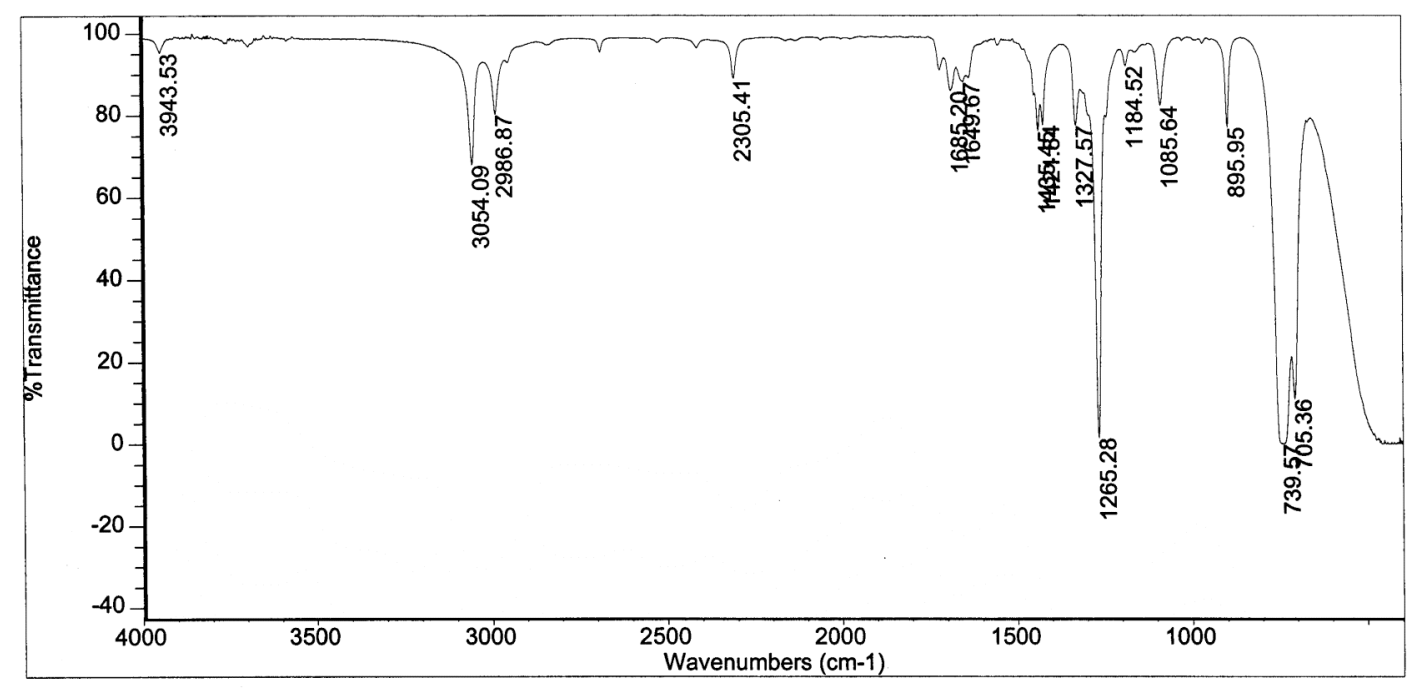

Figure S6. EI-MS dibenzothiophenium biscarbomethoxymethylide.

Retention time: $13.3 \mathrm{~min}$. 


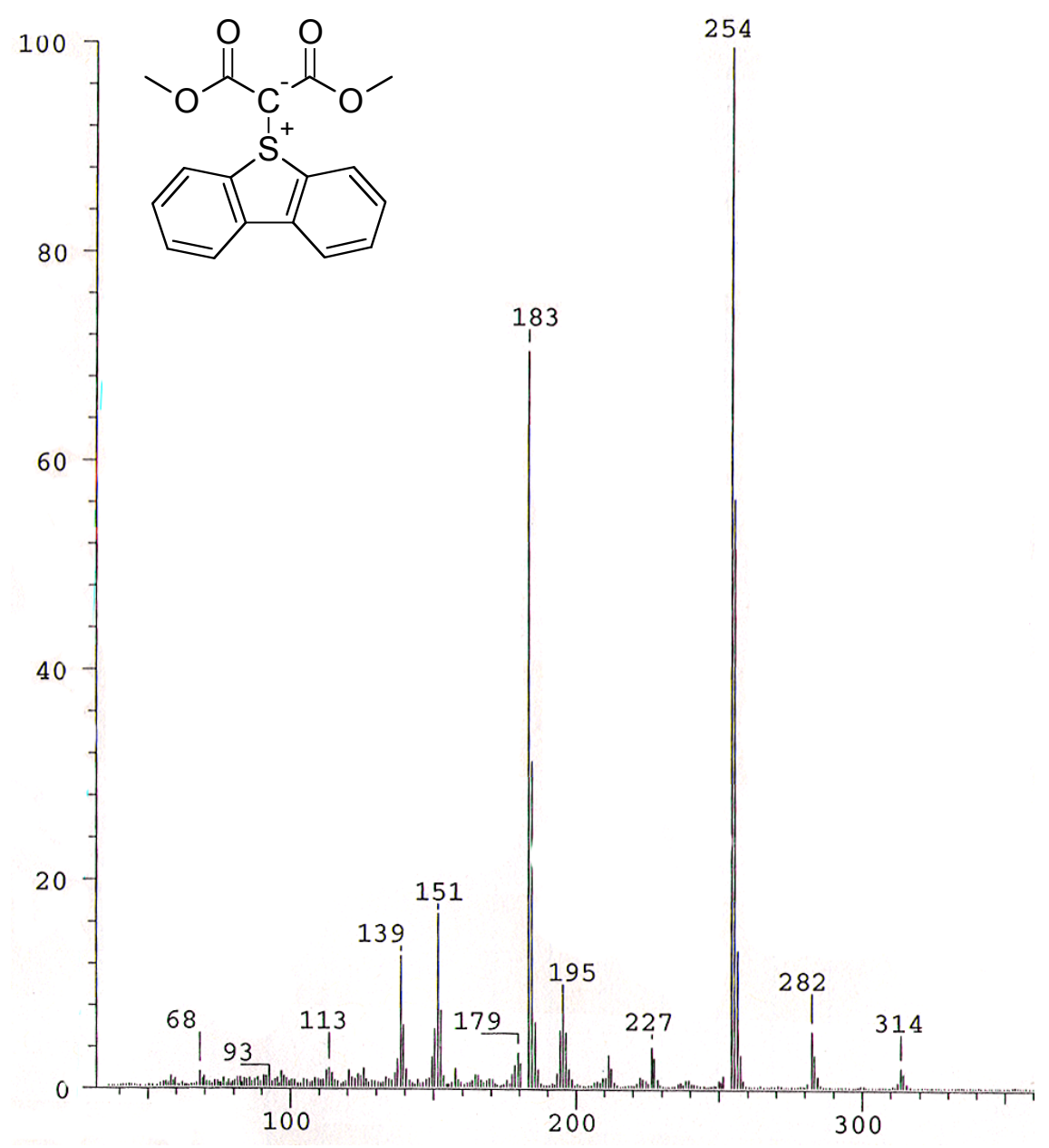

Steady state photolysis methods. All photolyses in this study were performed with one of two different photolytic systems. A Southern New England Ultraviolet Rayonet minireactor equipped with up to eight $4 \mathrm{~W}$ fluorescent bulbs was used in conjunction with a merry-go-round holder to ensure uniform irradiation. Low-pressure coated mercury lamps with broad emission around $300 \mathrm{~nm}$ and $350 \mathrm{~nm}$, as well as low-pressure mercury lamps with emission at $254 \mathrm{~nm}$ were used in this study. Samples were held in either a $1 \mathrm{~cm}$ quartz cell or an NMR tube.

The second photolytic system, used to measure quantum yields, was a $75 \mathrm{~W}$ Xenon Arc lamp coupled to a monochromator. The monochromator was set to the desired wavelength for 
photolysis and has $\pm 12 \mathrm{~nm}$ linear dispersion. Samples were held in $1 \mathrm{~cm}$ quartz cells and were magnetically stirred to ensure uniform irradiation.

Spectral grade solvents were used without further purification. All solutions were flushed with Ar for at least 15 min prior to photolysis to remove oxygen. The standard sample size was $3 \mathrm{~mL}$ in the $1 \mathrm{~cm}$ quartz cells.

Quantum yield measurements. Valerophenone was used as a chemical actinometer to determine quantum yields for photolyses performed at $300 \mathrm{~nm} \cdot{ }^{10,11}$ The actinometer was photolyzed in dry benzene at $300 \mathrm{~nm}$ and the appearance of acetophenone was monitored by HPLC with a diode array detector set to monitor at $265 \mathrm{~nm}$. The reverse-phase separations were performed on an analytical Supelco C18 column. The eluting solvents were methanol and acetonitrile. In a typical run, the initial ratio of solvents was $70 \%$ methanol and $30 \%$ acetonitrile. After injection of the sample, the solvent ratio was gradually changed to $50 \%$ methanol and $50 \%$ acetonitrile over a period of $10 \mathrm{~min}$ with a flow rate of $1.0 \mathrm{~mL} / \mathrm{min}$.

Azoxybenzene was used as a chemical actinometer to determine quantum yields for photolyses performed at $254 \mathrm{~nm} .{ }^{12,13}$ The actinometer was photolyzed in a solution of ethanol and potassium hydroxide and the appearance of 2-hydroxyazobenzene was monitored by the optical density at $458 \mathrm{~nm}$.

The quantum yields of $S, C$-sulfonium ylide decay and sulfide growth were determined by photolysis at either $254 \mathrm{~nm}$ or $300 \mathrm{~nm}$ with a $75 \mathrm{~W}$ Xenon Arc lamp and monochromator. The reactions were carried out to low conversion $(\leq 15 \%)$ in order to remain in the linear region of conversion. Uncertainties are reported as the standard error of the quantum yield. The progress of the reactions was monitored by HPLC with a diode array detector set to monitor at $265 \mathrm{~nm}$, 
$300 \mathrm{~nm}$ and $320 \mathrm{~nm}$. The reverse-phase separations were performed on an analytical Supelco C18 column.

For compounds 1-2, the ylide and sulfide were separated using an isocratic HPLC run in which the eluting solvents were water (30\%), methanol (20\%), and acetonitrile (50\%). Each run time was $10 \mathrm{~min}$ with a flow rate of $1.0 \mathrm{~mL} / \mathrm{min}$. The quantum yields for compounds 3-4 were determined by HPLC; the eluting solvents were methanol and acetonitrile. In a typical run, the initial ratio of solvents was $70 \%$ methanol and $30 \%$ acetonitrile. After injection of the sample the solvent ratio was gradually changed to $50 \%$ methanol and $50 \%$ acetonitrile over a period of 10 min with a flow rate of $1.0 \mathrm{~mL} / \mathrm{min}$.

Cyclohexene trapping. In a typical trapping study, the concentration of sulfonium ylide was sufficiently high such that the absorbance of the sample at the wavelength of irradiation was above 2.0 , which typically corresponded to $2-4 \mathrm{mM}$ solutions. The sulfonium ylide was dissolved in $9 \mathrm{~mL}$ of acetonitrile, sonicated for $5 \mathrm{~min}$ to ensure complete dissolution, and filtered. To this solution, $1 \mathrm{~mL}$ of cyclohexene was added. The mixture was flushed with argon for 15 min prior to photolysis. Compounds 5 and $\mathbf{6}$ were identified on the basis of known ${ }^{1} \mathrm{H}$ NMR spectra. ${ }^{6,7}$

Methanol trapping. In a typical direct photolysis, the concentration of the ylide was sufficiently high such that the absorbance of the sample at the wavelength of irradiation was above 2.0, which corresponded to 2-4 $\mathrm{mM}$ solutions. The ylide was dissolved in methanol, sonicated for $5 \mathrm{~min}$ to ensure complete dissolution, filtered, and flushed with argon for $15 \mathrm{~min}$ prior to photolysis. The identity of methyl methoxymalonate $(\mathbf{8})$ was established through its known NMR spectrum. ${ }^{14}$ When using $\mathrm{CD}_{3} \mathrm{OD}$ as solvent, 1,4-dioxane was used as an internal standard for integration and spectra were obtained at various levels of conversion. In $\mathrm{CD}_{3} \mathrm{OD}$, 
the observed chemical shifts of 8 are $4.57(\mathrm{~s}, 1 \mathrm{H}), 3.78(\mathrm{~s}, 6 \mathrm{H}), 3.46(\mathrm{~s}, 3 \mathrm{H})$. The chemical shifts for methyl malonate in the same solvent are $3.72(\mathrm{~s}, 6 \mathrm{H}), 3.44(\mathrm{~s}, 2 \mathrm{H})$. After complete photolysis, the methanol was removed in vacuo and ${ }^{1} \mathrm{H} \mathrm{NMR}$ were re-obtained using $\mathrm{CDCl}_{3}$ for final confirmation. Compound $\mathbf{1 0}$ was identified on the basis of its known NMR spectrum. ${ }^{15}$

Benzophenone sensitized photolysis. In a typical sensitized photolysis, the concentration of sensitizer was sufficiently high $(\sim 100 \mathrm{mM})$ such that it absorbed at least $99.9 \%$ of the light at the wavelength of irradiation. The sensitizer and S,C-sulfonium ylide were dissolved in methanol, sonicated for $5 \mathrm{~min}$ to ensure complete dissolution, filtered, and flushed with argon for $15 \mathrm{~min}$ prior to photolysis.

All reactions were monitored by HPLC, ${ }^{1} \mathrm{H}$ NMR, and GCMS. In a typical GCMS run (EI, DB-5 column $)$ the initial temperature $\left(180^{\circ} \mathrm{C}\right)$ was held for 5 min. The temperature was then raised at a rate of $10{ }^{\circ} \mathrm{C} / \mathrm{min}$ until a final temperature of $280^{\circ} \mathrm{C}$ was reached, at which point the temperature was held for $5 \mathrm{~min}$. The products were identified by comparison with data from authentic samples. All reported photolysis data represent experiments performed in at least triplicate or greater. The standard errors of the product yields are provided.

\section{References}

(1) Peace, B. W.; Carman, F.; Wulfman, D. S. Synthesis 1971, 658-61.

(2) Curphey, T. J. Org. Prep. Proc. Intl. 1981, 13, 112-115.

(3) Ando, W.; Yagihara, T.; Tozune, S.; Imai, I.; Suzuki, J.; Toyama, T.; Nakaido, S.; Migita, T. J. Org. Chem. 1972, 37, 1721-7.

(4) Gillespie, R. J.; Murray-Rust, J.; Murray, R., P.; Porter, A. E. A. J. Chem. Soc. Chem. Commun. 1978, 83-84. 
(5) Gysling, H. J.; (Eastman Kodak Co., USA). Application: US

US, 1976, p 5 pp Division of U S 3,860,500.

(6) Müller, P.; Tohill, S. Tetrahedron 2000, 56, 1725-1731.

(7) Wulfman, D. S.; McGibboney, B. G.; Steffen, E. K.; Nguyen, V. T.; McDaniel, R. S., Jr.; Peace, B. W. Tetrahedron 1976, 32, 1257-65.

(8) Ando, W.; Hagiwara, T.; Migita, T. Bull. Chem. Soc. Jpn. 1975, 48, 1951-2.

(9) Bowles, T.; Gillespie, R. J.; Porter, A. E. A.; Rechka, J., A.; Rzepa, H. S. J. Chem. Soc. Perkin Trans. I 1988, 803-807.

(10) Wagner, P. J.; Kemppainen, A. E. J. Am. Chem. Soc. 1968, 90, 5896-7.

(11) Wagner, P. J.; Kochevar, I. E.; Kemppainen, A. E. J. Am. Chem. Soc. 1972, 94, 7489-94.

(12) Bunce, N. J.; LaMarre, J.; Vaish, S. P. Photochem. Photobiol. 1984, 39, 531-533.

(13) Gauglitz, G. J. Photochem. 1976, 5, 41-47.

(14) Ando, W.; Hagiwara, T.; Migita, T. Bull. Chem. Soc. Japan 1975, 48, 1951-1952.

(15) Weinstock, L. M.; Corley, E.; Abramson, N. L.; King, A. O.; Karady, S. Heterocycles 1988, 27, 2627-2633. 